\title{
Short-and Long-Term Clinical Outcomes of Infliximab in Fulminant Ulcerative Colitis
}

\author{
J. Florholmen, ${ }^{1,2}$ G. Øverland, ${ }^{1}$ T. Olsen, ${ }^{2}$ R. Rismo, ${ }^{1}$ G. Cui, ${ }^{1,2}$ I. Christiansen, ${ }^{1}$ \\ E. J. Paulssen, ${ }^{1,2}$ and R. Goll ${ }^{1,2}$ \\ ${ }^{1}$ Laboratory of Gastroenterology, Institute of Clinical Medicine, University of Tromsø, 9037 Tromsø, Norway \\ ${ }^{2}$ Department of Medical Gastroenterology, University Hospital of North Norway, 9037 Troms $\varnothing$, Norway
}

Correspondence should be addressed to J. Florholmen, jon.florholmen@unn.no

Received 16 September 2010; Revised 3 December 2010; Accepted 14 December 2010

Academic Editor: Kazunari Tominaga

Copyright () $2011 \mathrm{~J}$. Florholmen et al. This is an open access article distributed under the Creative Commons Attribution License, which permits unrestricted use, distribution, and reproduction in any medium, provided the original work is properly cited.

\begin{abstract}
The aim was to characterize short- and long-term clinical outcomes of infliximab in fulminant ulcerative colitis. Patients with severe ulcerative colitis meeting the criteria of fulminant colitis after 3 days of glucocorticosteroid treatment were randomized to control or additional induction therapy of infliximab followed by an on demand/maintenance therapy of infliximab. Twenty six patients with fulminant colitis were equally randomized. At Day 7, ten patients in the control group and none in the infliximab group were in the need of colectomy $(P<.001)$. Due to superior effect of infliximab, patients in the control group were of ethical reasons transformed to infliximab treatment instead of performing colectomy. The probability to avoid colectomy was 0.66 with a median observation time of 52 months and a maximal of 91 months. The addition of azathioprine reduced the risk of late colectomy. We conclude that infliximab is effective in preventing early and late colectomy in fulminant colitis.
\end{abstract}

\section{Introduction}

Ulcerative colitis (UC) is a chronic inflammatory bowel disease (IBD) in which the pathogenesis is believed to result from combined environmental factors, genetic factors, and immune responses to luminal antigens. UC has been considered to be an atypical $\mathrm{T}$ helper 2 ( $\mathrm{TH} 2$ ) driven disease, with a pathogenesis suggested to be influenced by other cytokines than Tumor necrosis factor alpha (TNF- $\alpha$ ) [1-3]. However, considering the report of increased IFN$\gamma$-the original TH1 defining cytokine-in UC [1], the immune response in $\mathrm{UC}$ is a mixed TH response as discussed elsewhere [4]. TNF- $\alpha$ and the T cell profile both play roles in the pathogenesis of IBD and especially in Crohn's disease, whereas their roles in UC are still debated [5-9]. We have recently demonstrated an increased TNF- $\alpha$ gene expression level in inflamed colorectal mucosa in UC by real-time PCR, confirmed by immunohistochemical examination. In that study, mucosal TNF- $\alpha$ mRNA levels correlated well with the endoscopic inflammation score [10]. Other groups have also demonstrated increased TNF- $\alpha$ levels in colorectal mucosa and stool in IBD patients $[11,12]$.
Infliximab (IFX), an anti-TNF- $\alpha$ antibody, has been shown to be effective in the treatment of moderate to severe ulcerative colitis $[13,14]$. The randomized doubleblind multicenter placebo-controlled ACT1 and ACT2 trials reported a clinical remission at 8 weeks of $38.8 \%-33.9 \%$, versus $14.9 \%-5.7 \%$ in the placebo group [14]. We have shown that after treatment with IFX the mucosal TNF- $\alpha$ mRNA levels were reduced to levels equal to healthy controls [15], and pretreatment levels of mucosal TNF- $\alpha$ mRNA negatively predicted the clinical response of this biological agent [16].

There are few reports on the effect of anti-TNF in the most severe form of ulcerative colitis, namely, fulminant ulcerative colitis as described by Truelove and Witts in 1954 [17]. There are some uncontrolled studies indicating that infliximab can reduce the risk of colectomy in the short perspective (for review, see [18]), whereas in the only controlled study, infliximab was reported to be a rescue treatment for patients who qualified for colectomy during the first 3 months [13]. However, there are no longterm controlled studies of infliximab calculating the risk of colectomy in fulminant ulcerative colitis. 
Therefore, we performed a randomized controlled study of IFX in severe ulcerative colitis to characterize short- and long-term clinical outcome.

\section{Materials and Methods}

2.1. Study Design. Patients with severe UC were screened $($ Day -3$)$ for later enrollment in the study. The patients who did not respond to i.v. corticosteroid medication after three days (Day 0) and who met the criteria of fulminant ulcerative colitis according to Truelove and Witts [17] were included in the study in a randomized, controlled open-label design. The patients were randomized to either further steroid treatment alone (control group) or steroids in combination with infliximab at $5 \mathrm{mg} / \mathrm{kg}$ body weight (active group). At Day 7 the two groups were evaluated for treatment response: with and without being colectomized and/or in the need of colectomy according to the general guidelines. The patients in either group not in the need of surgical treatment at Day 7 received additional treatment with azathioprine. The active and control groups were regularly followed up with clinical controls with tapering of the steroid treatment whereas patients in the active group were treated with additional infusions of infliximab at 2 and 6 weeks (Day 42). Patients with fulminant colitis without an initial response to i.v. corticoteroid treatment had 30\% risk of needing an early colostomy [17]. Due to the initial good response in the active group compared to the control group, the plan of an open randomized controlled design beyond Day 7 was abandoned due to ethical considerations. Therefore, at Day 7, patients in the control group without clinical effect, that is, still meeting the criteria of fulminant colitis, and still without need of acute colectomy, were given infliximab. After Day 42 the patients were followed up on an individual basis according to the practice in the gastrointestinal unit. There was a continuous evaluation of the need for colectomy. The study design is shown in Figure 1.

All participants were informed and signed a written consent. The study was approved by The Regional Committee of Medical Ethics of North Norway, the Norwegian Social Science Data Services, and the Norwegian Medicine Agency.

2.2. Patients and Methods. In this study, UC patients with severe disease activity admitted at the University Hospital of North Norway were screened for participation of the study in the period of January 1, 2003 to January 1, 2005 and a followed up until to June 1, 2010. The diagnosis was based on established clinical, endoscopic and histological criteria [19]. The degree of illness was evaluated using the clinical scoring system, Ulcerative Colitis Disease Activity Index (UCDAI) (score 0-12) [20], and score $\geq 8$ was defined as severe. The inflammation of colonic mucosa was graded (grade 0-3) during endoscopy using the UCDAI endoscopic subscore [21]. Mucosal healing was defined as sub-score 0 or 1 during the endoscopy re-examination [22]. Criteria for fulminant colitis were (1) no need of acute surgery defined by the clinician and (2) either at least 8 daily bowel movements (from day -3 to Day 0 ) or $>3$ movements daily with Creactive protein $(\mathrm{CRP})>45 \mathrm{mg} / \mathrm{L}$, which corresponds to a fulminant colitis index (number of daily bowel movements $+(0.14 \times \mathrm{CRP}>8 \mathrm{mg} / \mathrm{L})$ of $\geq 8$ [23]). Complete response to therapy (clinical remission) was defined as reduction of UCDAI score to $<3$ together with an endoscopic sub-score of 0 or 1 [24]. Clinical response to therapy was defined as a decrease in the total UCDAI score of at least 3 points from baseline [24], improvement defined as reduction of UCDAI score of $1-3$, whereas nonresponse defined as no reduction in UCDAI score.

Exclusion criteria were age $<18$ years, pregnancy, or planned pregnancy in the next 15 months, actual or past active/inactive tuberculosis, severe ulcerative colitis with clinical signs of toxic dilatation of colon and/or perforation, infections that according to the clinician were contraindicated for IFX treatment, severe disease and known hypersensitivity to infliximab.

Blood wasdrawn for erythrocyte sedimentation test (ESR), CRP, hematology, creatinine, albumin and liver function tests at all registration time points. Other tests of blood and feces were performed when indicated. A radiological lung and plain abdominal test were performed. Adverse events were registered.

\subsection{Screening, Induction Therapy, and Registrations}

\section{Screening}

Day -3 to 0 . In patients with suspicion of severe ulcerative colitis at admittance (Day -3), a sigmoidoscopy was performed for the grading of inflammation, and biopsies were taken for histological examination. The patients were treated with a daily dose of $60 \mathrm{mg}$ methylprednisolone (Solu-Medrol, Pfizer, Oslo, Norway). Patients with severe ulcerative colitis and the other inclusion criteria and no exclusion criteria at Day -3 were included in the screening program.

Day 0-7. Patients who did not respond sufficiently to the i.v. glucocorticoid treatment and who met the criteria of fulminant ulcerative colitis according to Truelove and Witt [17] at Day 0 were randomized to either the control group, i.v. glucocorticosteroids alone, or the active group with the additional therapy of i.v. $5 \mathrm{mg} / \mathrm{kg}$ body weight infliximab (Remicade, Schering Plough, Oslo, Norway). The patients were clinically evaluated daily for additional therapy and for decision of surgical treatment. I.V. treatment with antibiotics and albumin were given if indicated on individual basis according to the judgment of the clinician. If no clinical improvement including the fulminant colitis index score $(\geq 8)$ at Day 7 was achieved, the patients were decided to perform surgery

At Day 7, a daily dose of $50 \mathrm{mgs}$ o.d. of azathioprine (Imurel GlaxoSmithKline, Oslo, Norway) was commenced, and increased to a maximum dose $2.5 \mathrm{mg} / \mathrm{kg}$ body weight. The i.v. doses of glucocorticoids were if indicated switched to $30 \mathrm{mg}$ of prednisolone (Prednisolon Nycomed Pharma, Oslo, Norway) with a weekly dose reduction of $5 \mathrm{mgs} /$ day. If not already on 5-aminosalicylic acid (5-ASA) medication, administration of a mesalazine-based medication was started. 


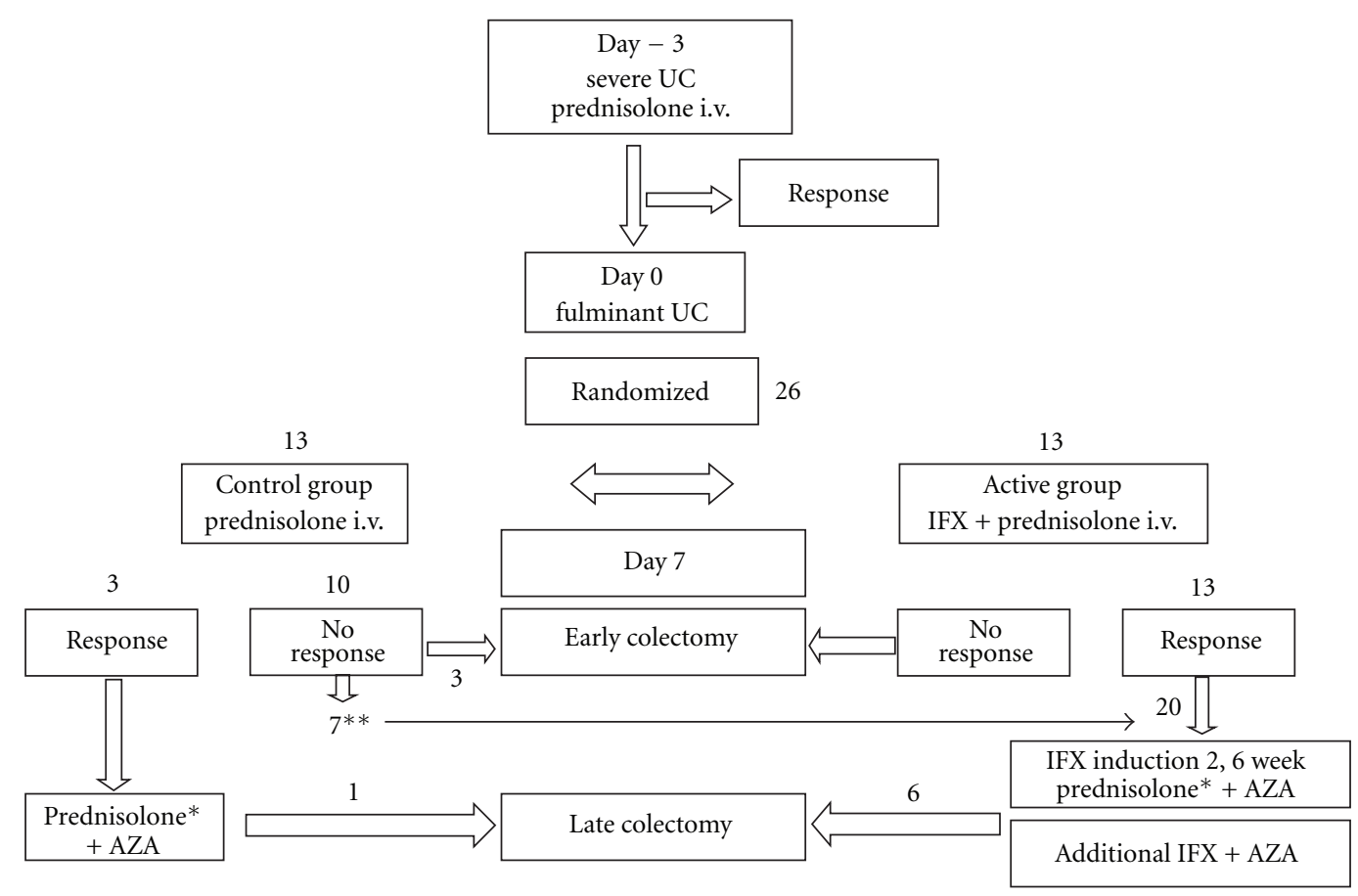

FIGURE 1: Flowchart of study. AZA: azathioprine, IFX: infliximab, UC: ulcerative colitis, ${ }^{*}$ in tapering doses, ${ }^{* *}$ converted to infliximab, see text.

At Day 7, the patients in the active group and the control group started with additional treatment unless acute colectomy was indicated. This included glucocorticoid, azathioprine, and 5-ASA regimen as described above.

Two weeks after the last infliximab infusion, a new registration with sigmoidoscopy and UCDAI scoring was performed.

2.4. Follow up, on Demand or Maintenance. After the fixed induction therapy $(0,2,6$ weeks) of infliximab the patients were treated according to the following: if not in remission, the patients got maintenance therapy (every 8 week) for at least 12-month. If remission was obtained after the induction therapy or after a 12 months maintenance therapy, the infliximab was stopped. If relapse within 3 months after obtained remission, the patient got a 12-month maintenance therapy. If relapse after 3 months after obtained remission, the patients were treated only on demand (new induction therapy and the procedure as described above).

The evaluation of later colectomy was made on a clinical decision and mostly due to lack of response.

2.5. Assessment of Treatment. Analyses were performed on the basis of intention to treat. The first evaluation of treatment was at Day 7 comparing the active and control group for the need of early colectomy. The patients that performed colectomy at Day 7 or later on were registered and thereafter withdrawn for further assessments. The effect of treatment in the group receiving induction therapy of infliximab was evaluated 2 weeks after the last infusion at Day 42.
2.6. Statistical Analyses. According to power estimates based on an expected early colectomy at day 7 of $15 \%$ in the infliximab group and $85 \%$ in the control group (corticosteroids alone), 13 patients in the active and 13 patients in the control group had to be enrolled at Day 0 to obtain a significant difference $(P<.05)$ between the two groups at $90 \%$ statistic strength.

The colectomy-free survival data was analyzed in two ways. (a): Intention to treat. All subjects in the control group who failed to respond at day 7 were withdrawn from the study and offered infliximab treatment (see above). By intention to treat, nonresponse to steroids after $3+7$ days treatment would most likely lead to early colectomy. Thus an analysis was run defining all nonresponders to steroid treatment as "having early colectomy". (b): Per protocol. As some of the patients in the control group eventually received infliximab, a second colectomy-free survival analysis was performed including all subjects who received anti-TNF treatment. This was done to estimate median colectomy-free survival time and overall risk of colectomy.

\section{Results}

3.1. Patients. Thirteen patients were included in each of the active and control groups. The demographic data at baseline are shown in Table 1. There were no significant differences between the two groups except for a higher age in the active group.

3.2. Outcome at Day 7. We observed clinical improvement in all patients in the active group and 3 of the patients in 
TABLE 1: Baseline characteristics in patients with fulminant colitis treated with infliximab in an opened randomized controlled open-label study.

\begin{tabular}{|c|c|c|c|}
\hline & Active & Control & $P$ \\
\hline Age & $47(29-66)$ & $27(15-76)$ & $.043^{*}$ \\
\hline $\operatorname{Sex}(M / F)$ & $8 / 5$ & $10 / 3$ & $\mathrm{Ns}^{\dagger}$ \\
\hline Tobacco (yes/no) & $0 / 13$ & $2 / 11$ & $\mathrm{Ns}^{\dagger}$ \\
\hline Duration of disease (years) & $1(0-19)$ & $0.5(0-10)$ & Ns* \\
\hline Localization of disease & $2 / 4 / 7$ & $1 / 3 / 9$ & $\mathrm{Ns}^{\dagger}$ \\
\hline \multicolumn{4}{|l|}{ Proctus/left colon/total } \\
\hline UCDAI score & $12(12-12)$ & $12(12-12)$ & $\mathrm{Ns}^{\dagger}$ \\
\hline \multicolumn{4}{|l|}{ Treatment at inclusion } \\
\hline 5-ASA (yes/no) & $7 / 6$ & $4 / 9$ & $\mathrm{Ns}^{\dagger}$ \\
\hline Immunosuppressive (yes/no) & $0 / 13$ & $1 / 12$ & $\mathrm{Ns}^{\dagger}$ \\
\hline \multicolumn{4}{|l|}{ Biochemistry } \\
\hline Hemoglobin (g/dL) & $11.7(6.8-16.1)$ & $12.7(9.3-14.1)$ & Ns* \\
\hline Albumin $(\mathrm{g} / \mathrm{L})$ & $32.6(22.1-43.9)$ & $32.9(23.4-38.4)$ & Ns* \\
\hline $\mathrm{CRP}(\mathrm{mg} / \mathrm{L})$ & $59(6-263)$ & $72(7-316)$ & Ns* \\
\hline $\operatorname{ESR}(\mathrm{mm} / \mathrm{h})$ & $41(15-97)$ & $32(14-65)$ & $\mathrm{Ns}^{*}$ \\
\hline
\end{tabular}

Continuous variables are median (min-max). Asterisk: Mann-Whitney; ${ }^{\dagger}$ Pearson Chi Square or Fishers Exact Test as appropriate.

the control group. The remaining 10 patients in the control group were assessed to be without improvement and thus in the need for a colectomy according to the general guidelines. Of these 10 patients, 3 underwent colectomy within the first week. By intention-to-treat analysis, the need for colectomy at Day 7 was significantly higher in the control group compared to the active treatment group $(P<.001$, Fishers Exact Test). After the first 3 patients in the control group had their colectomy, we had results indicating a strong effect of infliximab in the active group at Day 7. Therefore, after ethical considerations we decided to end the observation of the subsequent patients in the control group and convert them to infliximab treatment. This was to avoid performing a colectomy unless an absolute indication such as toxic megacolon and peritonitis were apparent. Thus, 13 patients in the active group and 7 patients in the initial control group had induction therapy with infliximab.

3.3. Outcome of Induction Therapy. The effect of the induction therapy of 3 infusions of infliximab at 0,2 , and 6 weeks is shown in Table 3. Remission was achieved in $45 \%$ of the patients.

3.4. Long-Term Outcome. During the observation time from 2005 to 2010, 17 of the 20 patients who had completed induction therapy had additional infusions of infliximab. No serious events were observed except for one patient with acute pancreatitis most likely due to azathioprine, and this medication was stopped. Additional six patients stopped medication of azathioprine due to adverse events (nausea). The number of patients on medication of 5-ASA and azathioprine was 12 and 12, respectively.

In the group who subsequently had colectomy, 1.3 (0-8) infusions per year were given, including 2 patients

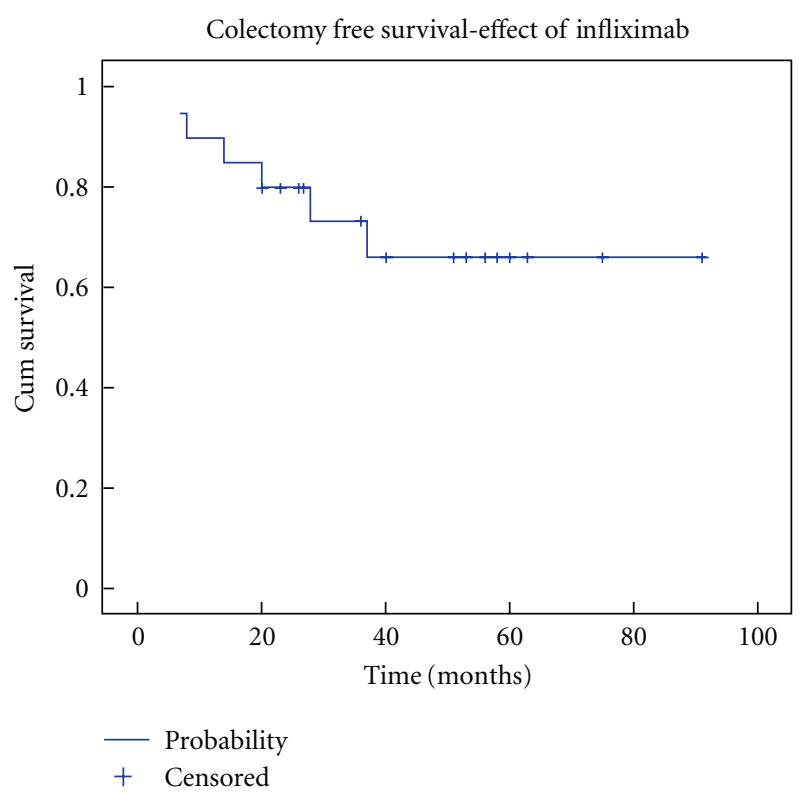

Figure 2: Cumulated colectomy free survival in the per protocol analysis. A total of 20 patients (13 in the infliximab group plus 7 from the control group) entered the analysis. Most colectomies were performed within the first 36 months, while after 50 months the group at risk is gradually reduced by censored observations.

on continuous maintenance therapy (8-week intervals), whereas in the group without colectomy, 1.9 infusions (06) per year were given, including 4 patients on continuous maintenance therapy (n.s.). Of interest was that of the 7 patients on infliximab treatment with late colectomy, none used azathioprine, whereas of the 14 patients on infliximab without late colectomy, 12 were on azathioprine medication $(P<.0005$, Fishers Exact Test). However, the study was 
TABLE 2: Late colectomy in patients with fulminant colitis.

\begin{tabular}{lcccc}
\hline & $\begin{array}{c}\text { Late } \\
\text { colectomy }\end{array}$ & $\begin{array}{c}\text { Time to late } \\
\text { colectomy }\end{array}$ & $\begin{array}{c}\text { No. without } \\
\text { colectomy }\end{array}$ & $\begin{array}{c}\text { Total observation } \\
\text { time without colectomy }\end{array}$ \\
\hline $\begin{array}{l}\text { Active } \\
\text { Control }\end{array}$ & $6 / 13$ & $17(7-37)$ & 7 & $60(26-91)$ \\
$\quad$ IFX & $0 / 7$ & $17(7-37)$ & 7 & $40(20-58)$ \\
All IFX & $6 / 20$ & & 14 & $52(20-91)$ \\
Control & $1 / 3$ & 12 & 2 & $19(2-36)$ \\
$\quad$ No IFX & & & & \\
\hline
\end{tabular}

Continuous variables are median (min-max). Time: in months. IFX: infliximab.

TABLE 3: Effect of induction therapy of infliximab in fulminant colitis.

\begin{tabular}{lcc}
\hline & number & $\begin{array}{c}\text { Remission : response: } \\
\text { improvement }: \text { non-response }\end{array}$ \\
\hline Active & 13 & $5: 6: 1: 1$ \\
Initial control & 7 & $4: 2: 1: 0$ \\
All & 20 & $9: 8: 2: 1$ \\
\hline
\end{tabular}

not primarily designed to investigate the additional effects of azathioprine.

The time to colectomy and the observation time without colectomy are shown in Table 2. According to the effects of the induction therapy of infliximab at Day 42 , colectomy was later performed in 2 out of 9 in the remission group, 4 out 8 patients in the response group, and 1 out of 3 patients in the nonresponder group. In Figure 2 the colectomy-free survival per protocol analysis is shown. The probability to avoid colectomy was 0.66 after a maximal observation time of 91 months. As only $24 \%$ had colectomy, a median colectomyfree survival time cannot be given, but the 75 percentile was 28 months.

The intention-to-treat analysis yielded a mean $(95 \% \mathrm{CI})$ colectomy free survival time of 56 months (35-76) for the infliximab group and 6 months $(0-13)$ for the control group $(P<.0005$ Log-rank; Mantel-Cox $)$

\section{Discussion}

In this study we have shown that anti-TNF treatment with infliximab in patients with fulminant ulcerative colitis significantly reduced the early ( 1 week) risk of colectomy when compared to the conventional steroid regimen. The induction therapy was followed by additional treatment with infliximab on demand, which yielded a mean colectomyfree survival time of 56 months compared to 6 months in the group with conventional corticosteroid treatment. Long-term data shows that patients with severe ulcerative colitis are in the need of colectomy in 30\% after one year despite glucocorticoid treatment [25], indicating that infliximab should be used to prevent colectomy in fulminant ulcerative colitis. Moreover, the addition of azathioprine further reduced the risk of late colectomy.
Our study confirms a previous randomized placebocontrolled study of infliximab in a one-dose design [13] as a rescue medication for early colectomy in fulminant ulcerative colitis, in which the colectomy rates within 3 months were $29 \%$ in the active group and $67 \%$ in the control group. In our study the first colectomy in the infliximab group was at 7 months, a longer time span that most likely is due to the design including induction treatment of 3 infusions followed by treatment on demand in the follow-up period. In uncontrolled studies, the risk of early colectomy in severe or fulminant colitis was in the range of $15 \%-53 \%$ within the first 3-4 months (for review, see [18]). Of interest is the study of Kohn et al. [26], showing that with the use of two ore more infusions of infliximab early colectomy (within 2 months) in severe steroidresistant ulcerative colitis was observed in only 2 out of 57 patients.

In our study, remission was obtained in $45 \%$ of the patients after induction treatment with 3 infliximab infusions. In a review of 34 studies with moderate to severe ulcerative colitis a comparable remission of $40 \%$ was achieved at 9-month followup [27].

The long-term effect of infliximab given as an induction treatment with subsequent treatment on demand showed a colectomy-free survival of $63 \%$ after 91 months. There are so far no randomized, placebo-controlled, long-term studies of infliximab on the prevention of colectomy. Longterm studies of severe/fulminant ulcerative colitis show that $30 \%$ of patients are colectomized after 1 year when using glucocorticoids [27], whereas 58\% were colectomized after 7 years on ciclosporin [28]. The long-term prevention of colectomy observed in our study is most likely due to the combined effect of infliximab and azathioprine. The use of azathioprine in combination with infliximab in IBD is under ongoing discussion with great controversies [29]. However, none of the patients $(0 / 7)$ who had late colectomy used azathioprine, whereas most of the patients (12/14) without colectomy used this medication.

The strength of this study is the long observation time. One weakness is the deviation from the control design after Day 7 due to ethical considerations. Our long-term results of the probability of avoiding colectomy are in great favor of infliximab treatment. Therefore, there will most likely be no strict controlled design in future long-term studies of fulminant colitis. Future randomized controlled studies 
should investigate effects of infliximab in the combination with various immunosuppressive treatments.

In conclusion, in this study infliximab seems to be effective in preventing early colectomy and to render a high probability of colectomy-free survival in patients with fulminant ulcerative colitis

\section{Conflict of Interests}

The authors have no financial interests in the substances used in the study.

\section{Acknowledgments}

The authors are thankful to Odd Sverre Moen, Marian Remijn, and Line Wilsgård for superb technical assistance. This study was supported financially by Northern Norway Regional Health Authority and Schering-Plough A/S, Oslo, Norway.

\section{References}

[1] G. Bouma and W. Strober, "The immunological and genetic basis of inflammatory bowel disease," Nature Reviews Immunology, vol. 3, no. 7, pp. 521-533, 2003.

[2] I. J. Fuss, M. Neurath, M. Boirivant et al., "Disparate $\mathrm{CD}^{+}$lamina propria (LP) lymphokine secretion profiles in inflammatory bowel disease: Crohn's sisease LP cells manifest increased secretion of IFN- $\gamma$, whereas ulcerative colitis LP cells manifest increased secretion of IL-5," Journal of Immunology, vol. 157, no. 3, pp. 1261-1270, 1996.

[3] F. Heller, P. Florian, C. Bojarski et al., "Interleukin-13 is the key effector Th2 cytokine in ulcerative colitis that affects epithelial tight junctions, apoptosis, and cell restitution," Gastroenterology, vol. 129, no. 2, pp. 550-564, 2005.

[4] L. Mayer, "Evolving paradigms in the pathogenesis of IBD," Journal of Gastroenterology, vol. 45, no. 1, pp. 9-16, 2010.

[5] R. B. Sartor, "Mechanisms of disease: pathogenesis of Crohn's disease and ulcerative colitis," Nature Clinical Practice Gastroenterology and Hepatology, vol. 3, no. 7, pp. 390-407, 2006.

[6] S. Dionne, J. Hiscott, I. D’Agata, A. Duhaime, and E. G. Seidman, "Quantitative PCR analysis of TNF- $\alpha$ and IL- $1 \beta$ mRNA levels in pediatric IBD mucosal biopsies," Digestive Diseases and Sciences, vol. 42, no. 7, pp. 1557-1566, 1997.

[7] A. Stallmach, T. Giese, C. Schmidt, B. Ludwig, I. MuellerMolaian, and S. C. Meuer, "Cytokine/chemokine transcript profiles reflect mucosal inflammation in Crohn's disease," International Journal of Colorectal Disease, vol. 19, no. 4, pp. 308-315, 2004.

[8] G. McCormack, D. Moriarty, D. P. O’Donoghue, P. A. McCormick, K. Sheahan, and A. W. Baird, "Tissue cytokine and chemokine expression in inflammatory bowel disease," Inflammation Research, vol. 50, no. 10, pp. 491-495, 2001.

[9] G. Y. Melmed and M. T. Abreu, "New insights into the pathogenesis of inflammatory bowel disease," Current Gastroenterology Reports, vol. 6, no. 6, pp. 474-481, 2004.

[10] T. Olsen, R. Goll, G. Cui et al., "Tissue levels of tumor necrosis factor-alpha correlates with grade of inflammation in untreated ulcerative colitis," Scandinavian Journal of Gastroenterology, vol. 42, no. 11, pp. 1312-1320, 2007.
[11] A. Akazawa, I. Sakaida, S. Higaki, Y. Kubo, K. Uchida, and K. Okita, "Increased expression of tumor necrosis factor- $\alpha$ messenger RNA in the intestinal mucosa of inflammatory bowel disease, particularly in patients with disease in the inactive phase," Journal of Gastroenterology, vol. 37, no. 5, pp. 345-353, 2002.

[12] F. Casellas, M. Papo, F. Guarner, M. Antolin, J. R. Armengol, and J. R. Malgelada, "Intraluminal colonic release of immunoreactive tumour necrosis factor in chronic ulcerative colitis," Clinical Science, vol. 87, no. 4, pp. 453-458, 1994.

[13] G. Järnerot, E. Hertervig, I. Friis-Liby et al., "Infliximab as rescue therapy in severe to moderately severe ulcerative colitis: a randomized, placebo-controlled study," Gastroenterology, vol. 128, no. 7, pp. 1805-1811, 2005.

[14] P. Rutgeerts, W. J. Sandborn, B. G. Feagan et al., "Infliximab for induction and maintenance therapy for ulcerative colitis," The New England Journal of Medicine, vol. 353, no. 23, pp. 2462-2476, 2005.

[15] T. Olsen, G. Cui, R. Goll, A. Husebekk, and J. Florholmen, "Infliximab therapy decreases the levels of TNF- $\alpha$ and IFN$\gamma$ mRNA in colonic mucosa of ulcerative colitis," Scandinavian Journal of Gastroenterology, vol. 44, no. 6, pp. 727-735, 2009.

[16] T. Olsen, J. Goll, G. Cui, I. Christiansen, and J. Florholmen, "Tissue expressions of TNF-alpha in colorectal mucosa as a predictor of clinical outcome from induction therapy with infliximab in ulcerative colitis," Cytokine, vol. 46, pp. 222-227, 2009.

[17] S. C. Truelove and L. J. Witts, "Cortisone in ulcerative colitis; preliminary report on a therapeutic trial," British medical journal, vol. 2, no. 4884, pp. 375-378, 1954.

[18] S. C. Ng and M. A. Kamm, "Therapeutic strategies for the management of ulcerative colitis," Inflammatory Bowel Diseases, vol. 15, no. 6, pp. 935-950, 2009.

[19] B. E. Sands, "From symptom to diagnosis: clinical distinctions among various forms of intestinal inflammation," Gastroenterology, vol. 126, no. 6, pp. 1518-1532, 2004.

[20] P. Marteau, C. S. Probert, S. Lindgren et al., "Combined oral and enema treatment with Pentasa (mesalazine) is superior to oral therapy alone in patients with extensive mild/moderate active ulcerative colitis: a randomised, double blind, placebo controlled study," Gut, vol. 54, no. 7, pp. 960-965, 2005.

[21] L. R. Sutherland, F. Martin, and S. Greer, "5-aminosalicylic acid enema in the treatment of distal ulcerative colitis, proctosigmoiditis, and proctitis," Gastroenterology, vol. 92, no. 6, pp. 1894-1898, 1987.

[22] P. Rutgeerts, W. J. Sandborn, B. G. Feagan et al., "Infliximab for induction and maintenance therapy for ulcerative colitis," The New England Journal of Medicine, vol. 353, no. 23, pp. 2462-2476, 2005.

[23] S. C. Lindgren, L. M. Flood, A. F. Kilander, R. Löfberg, T. B. Persson, and R. I. Sjödahl, "Early predictors of glucocorticosteroid treatment failure in severe and moderately severe attacks of ulcerative colitis," European Journal of Gastroenterology and Hepatology, vol. 10, no. 10, pp. 831-835, 1998.

[24] C. Su, J. D. Lewis, B. Goldberg, C. Brensinger, and G. R. Lichtenstein, "A meta-analysis of the placebo rates of remission and response in clinical trials of active ulcerative colitis," Gastroenterology, vol. 132, no. 2, pp. 516-526, 2007.

[25] W. A. Faubion, E. V. Loftus, W. S. Harmsen, A. R. Zinsmeister, and W. J. Sandborn, "The natural history of corticosteroid therapy for inflammatory bowel disease: a population-based study," Gastroenterology, vol. 121, no. 2, pp. 255-260, 2001. 
[26] A. Kohn, C. Prantera, A. Pera, R. Cosintino, R. Sostegni, and M. Daperno, "Infliximab in the treatment of severe ulcerative colitis: a follow-up study," European Review for Medical and Pharmacological Sciences, vol. 8, no. 5, pp. 235-237, 2004.

[27] J. P. Gisbert, Y. González-Lama, and J. Maté, "Systematic review: infliximab therapy in ulcerative colitis," Alimentary Pharmacology and Therapeutics, vol. 25, no. 1, pp. 19-37, 2007.

[28] S. Campbell, S. Travis, and D. Jewell, "Ciclosporin use in acute ulcerative colitis: a long-term experience," European Journal of Gastroenterology and Hepatology, vol. 17, no. 1, pp. 79-84, 2005.

[29] G. Van Assche, S. Vermeire, and P. Rutgeerts, "Immunosuppression in inflammatory bowel disease: traditional, biological or both?" Current Opinion in Gastroenterology, vol. 25, no. 4, pp. 323-328, 2009. 


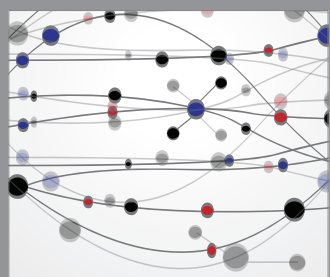

The Scientific World Journal
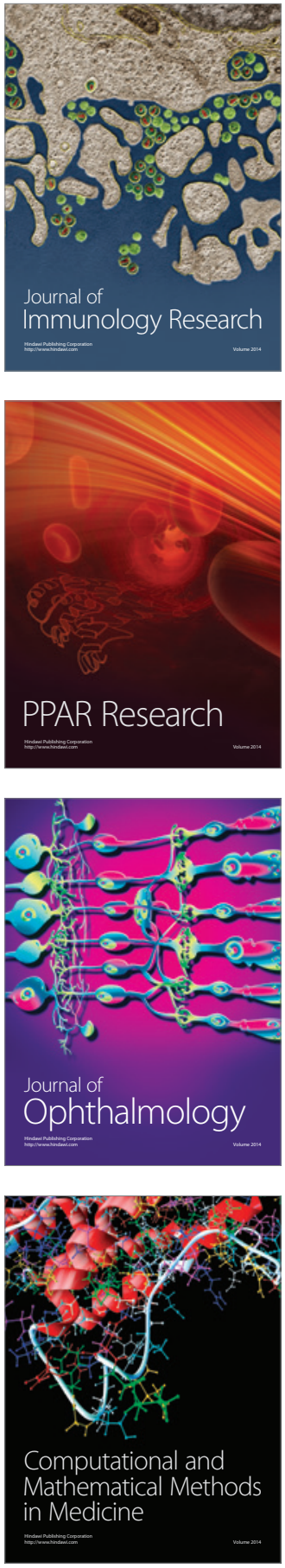

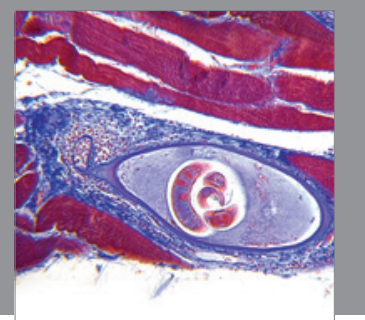

Gastroenterology

Research and Practice
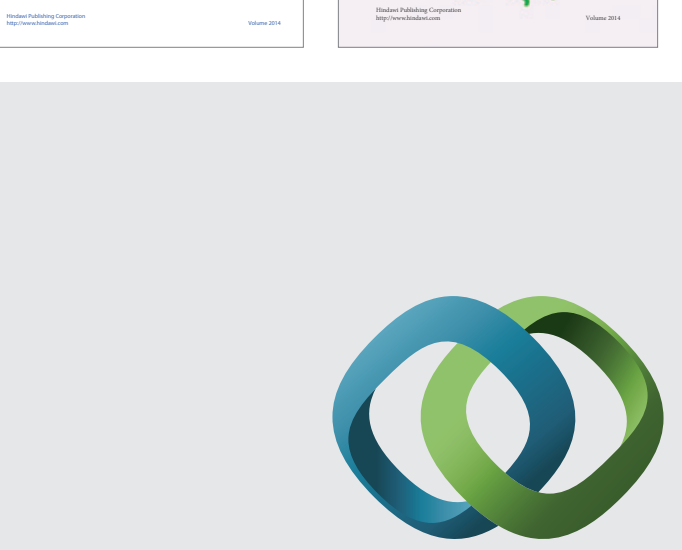

\section{Hindawi}

Submit your manuscripts at

http://www.hindawi.com
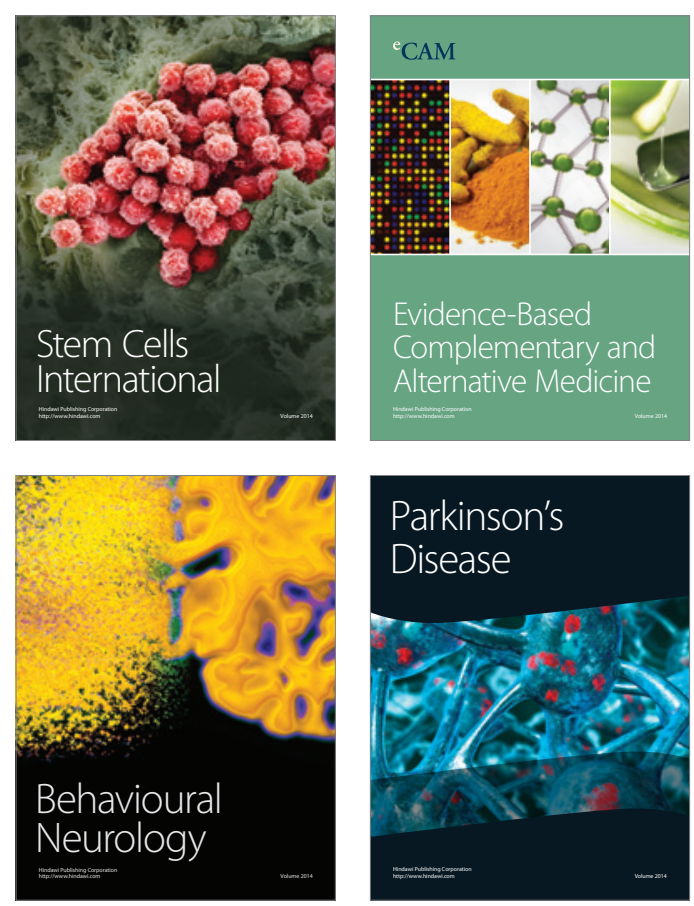

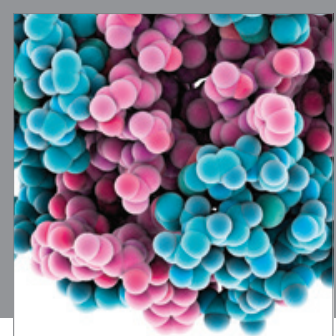

Journal of
Diabetes Research

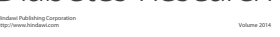

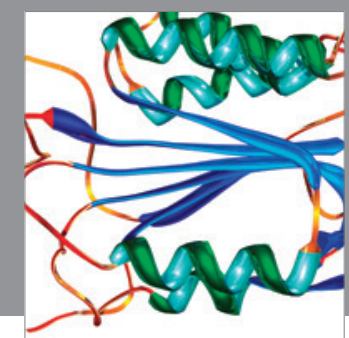

Disease Markers
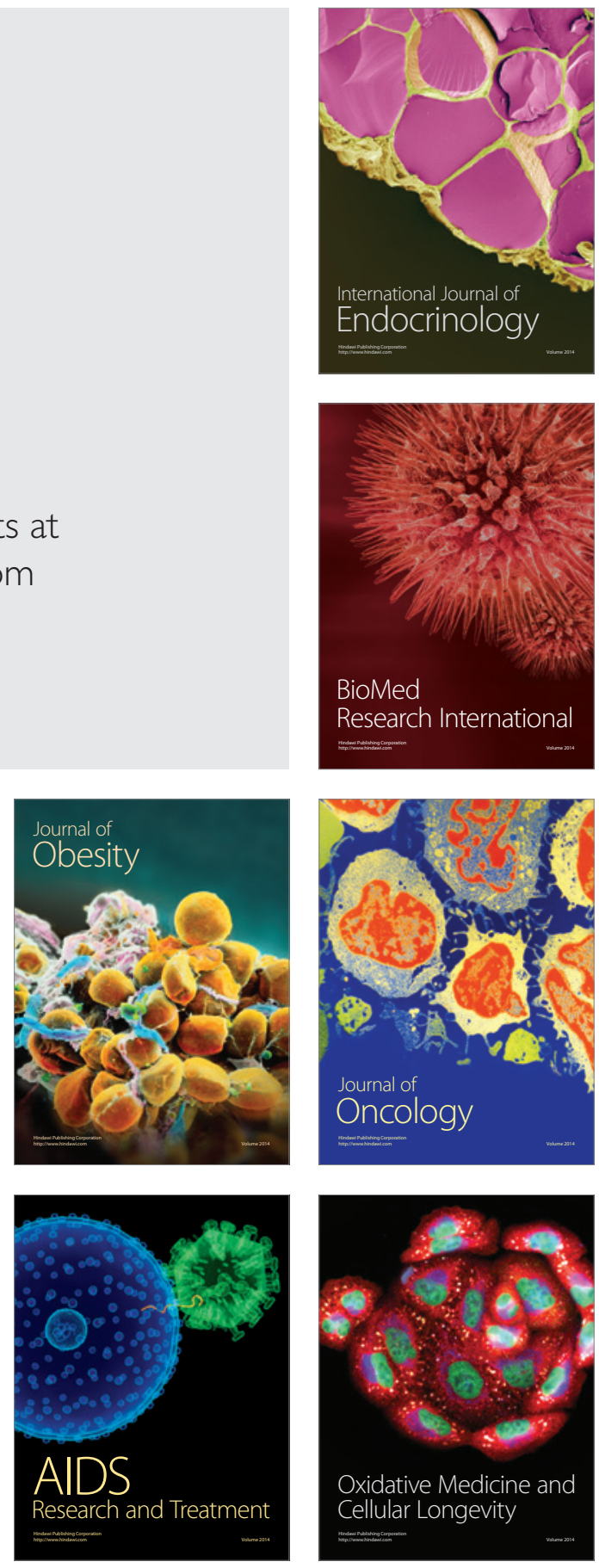